\title{
LOS EMBLEMATA PHYSICO-ETHICA DE NICOLÁS TAURELLO
}

\author{
Manuel Mañas Núñez
}

Universidad de Extremadura ${ }^{1}$

\begin{abstract}
Este artículo estudia la obra Emblemata physico-ethica (1595, 1602 y 1617) de Nicolás Taurello. Se tratan la obra y sus ediciones, las circunstancias de composición y las intenciones y temas del libro.

Keywords: Literatura emblemática, latín, naturaleza, ética.
\end{abstract}

\section{EMBLEMATA PHYSICO-ETHICA BY NICOLAUS TAURELLUS}

\section{Resumen}

This paper studies the work Emblemata physico-ethica (1595, 1602 and 1617) by Nicolaus Taurellus. The works and its editions, the circumstances of composition and the intentions and topics of the book are treated.

Palabras clave: Emblematic litterature, latin, nature, ethics.

${ }^{1}$ Este artículo se inscribe en la línea del Proyecto de Investigación FFI2017-82101-P, dirigido por el Dr. D. Luis Merino Jerez y subvencionado por el Ministerio de Economía, Industria y Competitividad.

Fecha de recepción: 19 de abril de 2018

Fecha de aceptación: 13 de mayo de 2019 
Nicolás Taurello, cuyo nombre verdadero era Nikolaus Öschslein, nació el 26 de noviembre de 1547 en Montbéliard, una población francesa situada en la región del Franco Condado, en el departamento de Doubs. Fue médico, filósofo y teólogo de adscripción luterana; y también, como podremos ver en el siguiente trabajo, un emblematista. Murió el 28 de septiembre de 1606 en Altdorf bai Nürnberg (Baviera), víctima de la peste. Fue un destacado humanista en la Alemania de la segunda mitad del siglo xvi y mereció los elogios de Leibniz (1768: 294), quien lo llamó ingeniosissimus y Scaliger Germanorum:

Haec ingeniosissimus Taurellus, quem ego Scaligerum Germanorum appellare soleo, stylo, acumine, ingenio, libertate sentiendi, medicinae professione simillimum.

[Tales cosas dijo el muy inteligente Taurello, al cual yo suelo llamar 'el Escalígero de los alemanes', pues es muy parecido a él en su estilo, en su agudeza, en su inteligencia, en su libertad de pensamiento y en el ejercicio de la medicina.]

Sus orígenes eran humildes, pues su padre era funcionario municipal, secretario del ayuntamiento de Montbéliard. Y, si pudo estudiar en la Universidad de Tübingen, fue gracias al mecenazgo y financiación del Duque Christoph von Württemberg (1515-1568). Discípulo de Jakob Degen (15111587), destacado representante de la neoescolástica protestante, Taurello se licenció en Medicina en 1563 y ya en 1565 tenía el grado de Magister en Filosofía. Ya en sus primeros escritos filosóficos se pronunció contra la autoridad de Aristóteles (Martin, 2014: 96-101) y abogó por una armonización de las enseñanzas teológicas y filosóficas.

Se trasladó luego a la Universidad de Basilea, donde se doctoró en 1570. Desde el año 1572 enseñó medicina en Basilea y en 1576 sucedió a Theodor Zwingers como catedrático de ética en la misma Universidad. Por estas mismas fechas, como sustituto del médico Isaac Cellarius, se hizo cargo de las clases de medicina. Y en 1580 fue llamado para ocupar una cátedra en la Universidad de Altdorf, donde llegó a ser catedrático de Medicina, de Física y Rector por cuatro veces. Ernst Soner, destacado unitarianista y socinianista, fue discípulo y colega suyo.

Respecto a su vida privada, fue escalando también posiciones sociales. Primeramente, se casó en 1578 con Katharina Aeschenberger, la hija del escribano de Altdorf, y, tras enviudar en 1598, se volvió a casar con Ursula Haller von Hallerstein, hija de un senador de Nuremberg.

Se le considera como el principal exponente del eclecticismo filosófico en la Universidad de Altdorf, en la misma línea que Juan Sturm (1507-1589) y, posteriormente, Conrado Feuerlein (1629-1704) o Jorge Rötenbeck (16481710). Desde sus primeros libros mantiene las posiciones de Melanchton: una genuina filosofía cristiana, que sólo reconoce la autoridad de la Biblia, 
como vemos, por ejemplo, en su Philosophiae triumphus, hoc est, metaphysica philosophandi methodus (1573). La ética de su exitoso libro de emblemas de 1595 está fundada en la concordancia entre la razón y la revelación bíblica y en dicho libro contemplamos su acercamiento filosófico a la ética bíblica. Combatiendo duramente el averroísmo y el panteísmo de los filósofos aristotélicos italianos, especialmente a Cesalpino, interpreta a Aristóteles a su modo e intenta maridar sus doctrinas con las del cristianismo reformado. Sus manifestaciones contra el principio de autoridad, su libertad de pensamiento, sus interpretaciones sobre la Trinidad, sus posiciones neoplatónicas y sus metas irenistas le llevan a ser considerado un ramista y un hereje, acusaciones todas de las que posteriormente fue defendido por Feuerlein ${ }^{2}$. Enseñando, en efecto, que la Providencia divina no se extiende más que a los seres racionales y sin profesar una servil admiración por la Escolástica aristotélica, no resulta raro que fuera acusado de socinianismo y ateísmo.

Combatió, pues, a la Escolástica aristotélica dominante en su época y se esforzó por construir un sistema filosófico donde la fe y la ciencia estuvieran en armonía, proponiendo para ello la necesidad de regresar al auténtico cristianismo. Profesa, entonces, el llamado Humanismo Cristiano. Reflejo de todo ello puede encontrarse en su obra Emblemata Physico-ethica, que lleva el subtítulo de Naturae morum moderatricis picta praecepta («Preceptos pintados de la naturaleza, reguladora de la moral»).

\section{LA OBRA Y SUS EDICIONES}

La obra, que sepamos, fue editada en tres ocasiones: en 1595, 1602 y $1617^{3}$.

La edición de 1595, con el título y subtítulo de Emblemata Physico-ethica, hoc est, Naturae morum moderatricis picta praecepta, está publicada en Nuremberg, por el editor Paulo Kaufmann, y firmada por el propio autor Nicolás Taurello, que indica su procedencia, calificándose como Montbelgardensis, y su categoría académica de catedrático de Física (esto es, Filosofía Natural o Ciencias Naturales) y Medicina en la Universidad de Altdorf: Physices et Medicinae in Altdorfensi Norica Academia professor. El propio autor nos dice en la portada de su obra que su colección de Emblemas es una compilación de sus observaciones naturales y que los ha redactado en poemas de metros variados (observata et vario conscripta carmine), si bien predomina el dístico elegiaco.

2 Cf. Jaumann (2004: 647), Groos (1894: 467-471); Lengenfelder (1977); Folaron (2002).

3 Utilizamos la segunda edición de 1602 para todas las citas y referencias en el texto con indicación del folio correspondiente. Pero, dado que en el original los folios están sin numerar, remitimos a los textos citados por las letras de los cuadernillos, teniendo en cuenta que las minúsculas corresponden a los preliminares y las mayúsculas a los emblemas propiamente dichos. Las traducciones al español son nuestras. 
Comienza la edición con una larga Ad lectorem praefatio, a la que siguen, sin más preámbulos, los emblemas (un total de 83), todos con una misma disposición formal: 1) el lema del emblema, que suele ser corto, partiendo a veces de un verso del poema emblemático, y alude al contenido del mismo; 2) la dedicatoria, con el nombre expreso del dedicatario del emblema (hay algunos sin dedicatario); 3) la pintura propiamente dicha que ilustra el contenido del lema y de los versos posteriores; 4) y, por último, los dísticos elegíacos, que sirven para entender la pintura y desarrollar el contenido moral que se quiere prescribir. La obra concluye con 51 emblemata nuda, a la espera de posibles dedicatarios que financien sus correspondientes grabados.

La edición de 1602, lleva el mismo título, pero la praefatio va precedida de una breve epístola nuncupatoria dirigida a los jóvenes Procopio y Pedro Pieniazeck de Krusslova, hijos de Iohannes Pieniazeck, magistrado jefe del distrito judicial de Cracovia (Davies, 2005: 45). Viene luego la citada praefatio, que coincide plenamente con la de 1595, si bien ahora va seguida de un poema de nueve dísticos elegíacos compuestos por Jerónimo Arconatus (Bogner, 1553-1599), destinados a defender a Nicolás Taurello, llamado ahora «filósofo alemán», contra un anónimo Caesalpinus philosophus Italus, que no es otro que Andreas Cesalpino (1519-1603), cuyas opiniones ya habían sido combatidas y rechazadas por Taurello en su libro Alpes caesae (1597), con un juego de palabras ilustrativo. A esta composición sigue otro poema encomiástico Sobre las obras filosóficas de Taurello (De operibus philosophicis CL. V. D. Taurelli Physici acutissimi), esta vez debido a la pluma del jurista Conrad Rittershausen (1560-1613). Aparecen a continuación los 116 emblemas, seguidos de otros 20 emblemata nuda.

La edición de 1617, cuando Taurello está ya muerto, es reedición de la de 1602 .

\section{Circunstancias de Composición}

Puede quizás llamar la atención que un filósofo y médico, autor de obras científicas de filosofía natural, metafísica y medicina, dedique parte de sus desvelos a la composición poética y decida publicar una obra de emblemática latina. Esto, que no era una rareza dentro del Humanismo del Renacimiento, le lleva a Taurello a escribir un largo prólogo donde se propone explicarnos los motivos y circunstancias de composición de sus Emblemata, así como su propia concepción sobre el género emblemático. Taurello es consciente de que en la fecha en que nos encontramos, a finales del siglo xvi, hay ya multitud de libros de emblemas publicados, además, por conspicuos autores. Pero el suyo, con esa faceta físico-ética, pretende ser original.

Lo primero, pues, que Taurello resalta es que, aunque ofrezca al lector un libro de emblemas, no se trata de una obra habitual. Su pretensión, como reza 
el título Emblemata physico-ethica, es brindarnos una visión de las realidades de la naturaleza y animarnos a observar con mayor detenimiento las cosas que ocurren en el mundo natural, pues de ahí podremos obtener experiencias y apreciar comportamientos con los que guiar nuestra vida humana y regular nuestras costumbres y nuestra moral. Se trataría, pues, de observar lo que ocurre en el mundo natural e imitarlo en nuestras vidas y acciones:

Naturam hic habes viventem et prudentem, optimam vivendi ducem morumque moderatricem (a4r).

[Aquí tienes a la naturaleza viviente y prudente, óptima guía de la vida y reguladora de la moral.]

Pero, claro está, no nos está presentando una obra filosófica, sino emblemática; por ello, también advierte que junto a esta visión de la naturaleza ofrece al lector unos versus emblematicos (a4r). Y, aunque confiesa que por su profesión de filósofo y médico se ha visto obligado a publicar obras científicas que realzaran su curriculum, la vocación poética la tuvo siempre presente desde niño y nunca la ha descuidado. Es más, a la hora de escribir un libro de emblemas, rechaza la idea de escribirlo en prosa, como había hecho recientemente Joaquín Camerario (1534-1598) con sus Centurias de Symbola et emblemata publicadas a partir de 1590 (Centuria I: 1590, II: 1595, III: 1596, IV: 1604). Taurello, que confiesa su vocación pedagógica e intenta que su mensaje llegue al mayor número de personas, tanto a sus discípulos como a los estudiosos de la física y medicina (a4v), decidió encapsular sus temas éticos en el ropaje de la poesía, pensando, como Lucrecio (4.18-25), que la medicina ético-moral es amarga, pero resulta más aceptable si se ofrece en una copa cuyos bordes estén endulzados con la miel de la poesía, que proporciona a la filosofía, además de elegancia estilística, una necesaria suavidad que hace que se lea y se asimile de forma más placentera:

In carmine sua tamen quaedam maior est quam in oratione soluta suavitas, qua nobis certe fuit opus vel maxime. Nam si quod metricum est nostrae demas orationi, quod reliquum erit omni vacabit elegantia nec cum voluptate legetur (c2r).

[Sin embargo, esa especie de suavidad suya, que para nosotros ha sido sumamente necesaria, es mayor en poesía que en prosa. Pues si quitas a nuestro discurso lo que está en metro, lo que quede carecerá de elegancia y no se leerá con placer.]

No obstante, Taurello se queja amargamente de las dificultades que ha tenido para ver publicado en forma de libro el fruto de sus desvelos. Los motivos que han hecho difícil su edición de emblemas han sido varios, pero el autor señala fundamentalmente tres: el desdén que sufre la filosofía frente 
al Derecho o la Teología; la inconstancia o ausencia de su grabador; y lo costoso de la edición.

En efecto, Taurello se lamenta de los tiempos que corren en Europa, especialmente en Alemania, donde, según nos confiesa, bien por el desprecio que sufren los estudios literarios, bien por el ambiente bélico reinante, resulta muy difícil publicar libros que no tengan que ver con el Derecho o con la Teología. A ello se suma el negocio editorial de libreros e impresores, que prefieren publicar libros de estas temáticas escolásticas, porque son los que se venden bien. Y esta queja la extiende Taurello a la realidad editorial de toda Europa, con la sola excepción de Italia, a cuyos nobles, nos dice, les interesa más la filosofía que la caza o las francachelas. En Alemania, en cambio, la filosofía se estima despreciable y nadie se dedica a su estudio salvo aquellos que se sienten seducidos por obtener cargos públicos y políticos. Pero, cuando han alcanzado su objetivo, rápidamente se olvidan de la filosofía y se libran de ella con suma alegría, como los prisioneros que salen de una cárcel y se encuentran ya libres. Taurello, en cambio, se siente rara avis dentro de este común desprecio por la filosofía y acaba asegurando que en su libro, si se excluye la forma poética, no habrá nada que no tenga que ver con las ciencias naturales y con la filosofía:

Sed ut sunt tempora, typographicae merces spretae iacent, nescio quo vel literarum contemptu vel iniuria bellorum... Quo etiam nomine iuris et Theologiae studia florent inter caetera maxime, Philosophica vero quo sint in precio, res ipsa evidenter docet. Italiam excipio, cuius nobilitati philosophia potissimum curae est loco venationis et compotationum... Nostris autem in regionibus nescio quid ipsa possit esse despectius... Nam si carminis rationem excipias, nihil in nostris erit emblematibus quod non vel physicum sit vel philosophicum (a4v-a5v).

[Pero, en los tiempos que corren, las mercancías tipográficas yacen desdeñadas, no sé por qué desprecio de las letras o por la injuria de las guerras... También con este pretexto, los estudios de Derecho y Teología florecen más que el resto de disciplinas, mientras que lo que valen los estudios filosóficos bien lo muestra y evidencia la propia realidad. Exceptúo a Italia, cuya nobleza se preocupa especialmente de la filosofía, en vez de dedicarse a la caza y a las francachelas... En cambio, en nuestras regiones no sé qué puede haber más despreciable que la filosofía... Pues si exceptúas la composición poética, nada habrá en nuestros emblemas que no tenga que ver con la física o con la filosofía.]

El segundo problema con el que Taurello se ha tenido que enfrentar ha sido su grabador de las pinturas (sculptor noster, c2v). Por su culpa la impresión de la obra se ha ido demorando más de lo debido, pues, por un lado, ha estado ocupado en otros asuntos y, por otro, se ha ausentado más tiempo del que Taurello esperaba. 
Y el tercer escollo, el más importante, ha sido el de costear la impresión. Un libro con grabados resultaba caro; ello aterraba a los impresores, que no estaban seguros de poder recuperar la inversión con la venta de los libros; y la maltrecha economía del autor no le permitía acometer esos elevados gastos. Así que Taurello y sus amigos idearon un método para poder costear la edición. El autor debía tener hechas ya numerosas composiciones poéticas, quizás acompañadas de dibujos a mano, que daba a conocer a sus amigos. Sus amigos entonces, nos cuenta, le impulsaron a publicarlas, haciéndose ellos cargo del asunto económico. Si Taurello accedía a dedicar a cada uno de los amigos un emblema, dejándoles añadir en la dedicatoria sus propios insignia, cada cual pagaría su propio emblema y así la edición no costaría nada al autor. De este modo, vemos que en la edición de 1595 son 83 los emblemas que aparecen dedicados a distintos personajes que habrían pagado por ello; y en la edición de 1602 tenemos esos mismos 83 emblemas, más otros 33, correspondientes a otros tantos personajes que habrían costeado el gasto de su propio emblema, hasta reunir el número total de 116 emblemas que constituyen esta segunda edición:

At typographos nimii sculpturae sumtus absterrebant. Vt vero meis id fieret sumptibus, res meae non ferebant. Quod cum mei convictores animadvertissent, hoc inierunt consilii et inter se constituerunt ut, si suum unicuique emblema tribueretur et dicaretur, facta insuper potestate qua, qui vellet, emblemati suo sua adiiceret insiginia, tantum quisque precii numeraret quantum ad unius emblematis sculpturam satis esset (a6r-v).

[Sin embargo, a los impresores les aterraba el enorme gasto que suponían los grabados y mi situación económica no me permitía a mí hacerme cargo de los gastos. Mis comensales se dieron cuenta de ello y decidieron y determinaron entre sí que, si destinaba y dedicaba a cada uno de ellos su propio emblema, dejándoles además a los que quisieran la potestad de añadir a su propio emblema sus propias distinciones (insignia), cada cual pagaría la suma que fuera necesaria para el grabado de este solo emblema.]

En cuanto al orden seguido en la relación de sus emblemas, confiesa Taurello que no hay orden alguno: se han ido sumando en el mismo orden en que sus dedicatarios se decidieron a cooperar económicamente en la publicación de la obra. No ha ordenado los emblemas según la dignidad de sus dedicatarios, poniendo delante a los de más alto rango y después a los de menor categoría, pues eso podía suscitar envidias, rivalidades y, en suma, problemas para él. Así que su solución ha sido sencilla: ha puesto «en primer lugar a quien antes se sumó a nuestra iniciativa y en último lugar a quién llegó el último» (a6v).

¿Y cómo se le ocurrió hacer un libro de emblemas físico-éticos? La idea debió de ser en Taurello un mero fruto de su propia profesión como filósofo 
de la naturaleza y médico. Pero no era una idea plenamente original. Ya antes que él, Nicolás von Reusner (1545-1602), procedente de una familia reputada de abogados y médicos, había publicado unos Emblemata partim ethica et physica, partim vero historica et hieroglyphica (Francoforti, 1581). Reusner pudo ser una de sus fuentes y quizás tomó de él la iniciativa de dedicar cada uno de sus emblemas a un personaje destacado que además sufragaría los gastos de impresión del mismo.

No obstante, Taurello nos explica que su proyecto de elaborar unos emblemas físico-éticos surgió de una forma pragmática y contemplativa. Él contempla lo que ocurre en la naturaleza y de ahí, mediante la meditación, extrapola y acomoda esos hechos a la vida humana y les da una dimensión ética. Es decir, elabora preceptos morales que, basados en lo que ocurre en la naturaleza, puedan servir para guiar nuestros comportamientos. Y nos pone dos ejemplos prácticos de cómo llegó a este proyecto. Un día vio a un obrero que, cortando leña, había clavado la cuña tan profundamente que no podía sacarla; sin embargo, tras despedazar el tronco con repetidos golpes, al final la cuña salió sola. Tras meditar sobre este hecho, forjó Taurello el precepto moral de que «hay que entregarse con constancia al esfuerzo que correctamente hemos emprendido, aunque no parezca que a corto plazo vayamos a obtener buenos resultados» (Recte suscepto labori constanter insistendum esse, licet non ita bene videatur esse successurus, a5v). Este precepto moral bien podía emplearse en la praxis médica, recomendando a los enfermos que, aunque a primera vista la medicación no haga efecto, hay que perseverar en ella y seguir los consejos médicos, porque al final, con insistencia y constancia, sanarán.

De esta experiencia, por tanto, surgió el emblema 37, que va dedicado a Michael Lorber de Bamberg y lleva por título Iterato liberor ictu («Me veo liberado tras repetidos golpes»):

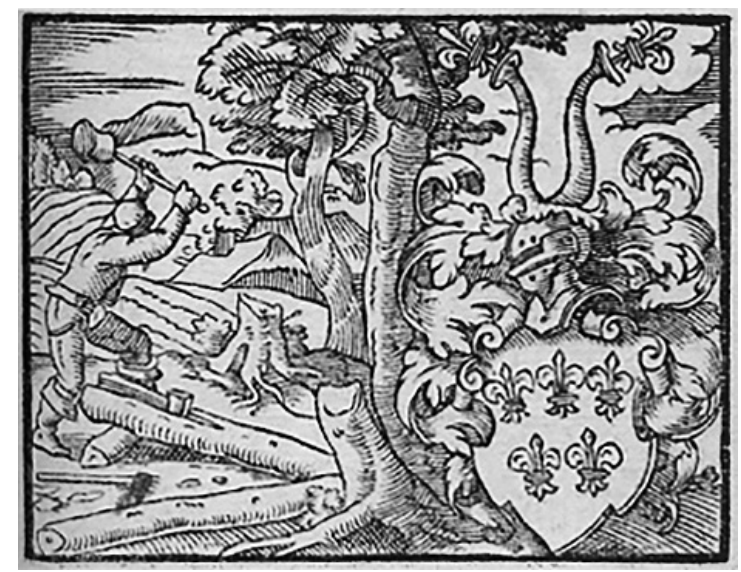

AEF, vol. XLII, 2019, 169-187 
Fixus in hunc cuneus qui magno est robore truncum,

Nullis evelli viribus inde potest.

Una sed ars superest, quam cognita causa docebit:

Ex immobilibus causa petenda labris.

Haec labra divellas iterato vulneris ictu

Et fracto cuneus carcere liber erit.

Si bene quid facias, suscepto insiste labori,

$\mathrm{Ne}$ sit quid frustra constituisse pudor (E5r).

[Clavada la cuña en este tronco que es de gran dureza,

no hay fuerza humana que pueda sacarlo de él.

Pero queda sólo la técnica que mostrará el conocimiento de la causa:

La causa hay que tomarla de los bordes inmóviles.

Tendrás que separar estos bordes con repetidos golpes

Y, rota la cárcel, saldrá libre la cuña.

$\mathrm{Si}$ haces algo bien, insiste en el esfuerzo asumido;

No te dé vergüenza haber establecido algo en vano.]

El segundo ejemplo que Taurello aduce también está tomado de sus experiencias y observaciones naturales. Paseando un día por el campo lleno de mieses, vio que, entre las muchas espigas abatidas y dobladas hacia abajo, había una erguida hacia las estrellas que se levantaba soberbiamente, y advirtió fácilmente el motivo de esta diferencia: que solo ella era más ligera por tener sus bolsas vacías de grano, mientras que las demás tenían que soportar la carga de densos granos. Y de ahí sacó el precepto de que «lo que nos convierte en soberbios no es el serio saber, sino la falsa opinión de erudición» (Non gravem doctrinam, sed falsam eruditionis opinionem superbos facere, a6r). Como muestra de que estas observaciones físicas le llevan a componer emblemas de contenido ético, veamos el emblema que salió de esta experiencia. Se trata del emblema 5, titulado Levitate superbit et exstat, dedicado y costeado por Chistoph Paul Gugel (1570-1617), de la rica e influyente familia Gugel de Nuremberg:

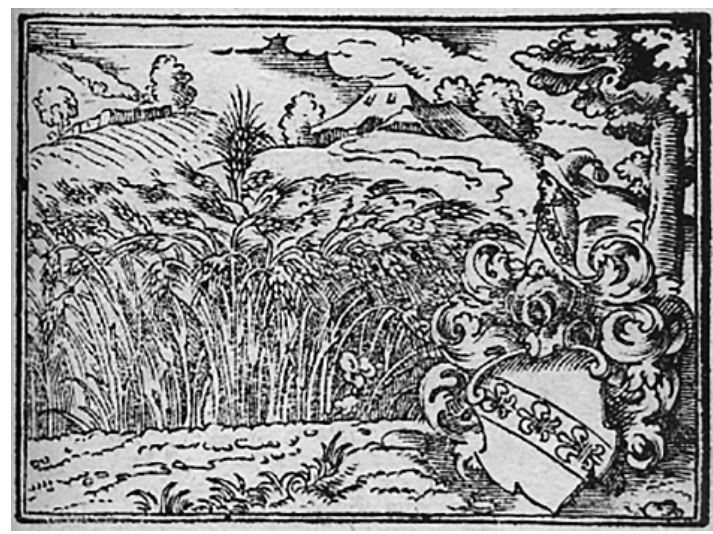

$A E F$, vol. XLII, 2019, 169-187 
Cernis ut optatis fecunda est messibus aestas

Et dominum quanto foenore ditet ager.

Una sed ecce alias supereminet inter aristas,

Quae celsa erectum tollit ad astra caput.

Scilicet haec multis, at inanibus aucta locellis

Effertur, dum nil quo retrahatur habet.

Quem levis assurgens effert doctrina, superbit.

Nam scit, qui doctum se putat esse, nihil (A5r).

[Ves cuán fecundo en deseadas mieses es el verano

Y con qué grandes ganancias enriquece el campo a su dueño.

Pero mira cómo entre las demás espigas sobresale una

Que eleva su erguida cabeza a las excelsas estrellas;

Esto es, al crecer con muchas bolsitas, pero vacías,

Se eleva a lo alto, pues no tiene nada que la arrastre hacia abajo.

Soberbio es aquel a quien un frívolo saber lo yergue y eleva,

Pues nada sabe quien se considera a sí mismo docto.]

Este emblema, en fin, según confiesa su autor, salió de su propia observación durante un paseo estival por el campo sembrado de cereales. Más tarde, con el lema Arrogantia sine fructu, lo veremos en uno de los emblemas de Juan de Borja para explicarnos la diferencia entre el hombre arrogante y engreído, representado por las espigas vacías, y el hombre modesto y humilde, simbolizado por las espigas que, cargadas de grano, se inclinan al suelo. También en las Empresas espirituales y morales de Juan Francisco de Villalva, con el lema Quia plena recumbor, se indica la idea de humildad, representando la espiga llena al buen cristiano repleto de virtudes, frente al hombre soberbio que está vacío de cualidades, a quien representa la espiga que, por estar vacía, aparece recta y empinada (Bernat y Cull, 1999: 323-325; Cacheda Barreiro, 2006: 190).

\section{Propósito y temas}

A pesar de que sus epigramas son de buena factura poética, Taurello se cura en salud frente a las posibles objeciones que pudieran lanzarle los literatos quisquillosos y confiesa que, aunque nunca dejó de cultivar la poesía, sus ocupaciones profesionales le robaron tiempo para perfeccionar su vena poética. Dice, además, que es consciente de que los tiempos han cambiado y que ahora los poetas, quizás preanunciando ya la llegada del Barroco, se preocupan sobre todo por la estética, por la pureza y elegancia de la lengua y por la forma poética (verba), anteponiendo todo ello a lo que se dice, a los temas (res). Censura, por tanto, a los poetas de su época que se preocupan más por el placer y el colorido de los temas que por los propios temas y su utilidad: «Voluptatem hoc nempe est rerumque colores ipsis rebus et utilitati praeferre» (a8r) [«Se trata, naturalmente, de poner 
el placer y el colorido de los temas por encima de los propios temas y de su utilidad»].

En este sentido, Taurello nos dice que él ha antepuesto las res a los verba. Y se dispone, pues, a hablarnos ampliamente sobre lo que para él supone la realidad emblemática, en donde ha contemplado tres aspectos: la materia de los emblemas, que es physica, esto es, la naturaleza como causa eficiente de donde nacen sus temas (res) emblemáticos; la forma, que es moralis, es decir, el enfoque ético de sus emblemas; y la ratio carminis, que sería el ornato exterior, el ropaje poético, los verba:

Ad rem ipsam accedamus, in qua materiam formamque et carminis rationem spectavimus. Materia physica est, formaque moralis, et ornatus exterior poeticus est $(\mathrm{a} 8 \mathrm{r})$.

[Pasemos a la realidad misma en la que hemos contemplado la materia, la forma y la razón de los poemas. La materia atañe a la física; la forma, a la moral; y el ornato exterior a la poesía.]

Y sobre lo que más se extiende en sus explicaciones, que constituyen una especie de doctrina propia emblemática, es sobre la materia. En concreto, nos expone que la emblemática es un género literario y cuasifilosófico que, huyendo de la especulación y del análisis demostrativo, lo que pretende es más bien ilustrar de forma placentera y atractiva cosas que ya los filósofos demostraron anteriormente. Nos dice, asimismo, que su fin puede ser doble: ilustrar una cosa ya demostrada para que se entienda mejor; o adornarla y condimentarla para que cause placer. Para ilustrar eso que ya está demostrado se usan dos modalidades de similitudes: el ejemplo y la parábola. Y precisamente de la parábola deriva el género de los emblemas, cuyo fin no es demostrar los temas en sí, sino ilustrarlos y adornarlos para que se comprendan mejor y más placenteramente (a8r-v). Visto todo lo cual, nos ofrece Taurello su definición del emblema como una descripción de las cosas de la naturaleza, tras la que está la mano de Dios, para que las evitemos, si son vicios, y las imitemos, si son virtudes. Los emblemas son, en palabras del propio Taurello:

Emblemata ergo... moralium sunt virtutum aut vitiorum in variis DEI et naturae operibus expressae picturae, quas recte comtemplati ad usus nostros magna cum voluptate accomodamus, modo qui noster sit, non DEI vel naturae... Sed tum demum naturamque Deumque dicemur esse imitati, quando ad ea quae nobis a DEO et natura in hoc universo virtutum obiecta sunt exemplaria nostros mores compusuerimus. Natura namque bene beateque vivendi dux est optima (b1r-v).

[Así pues, los emblemas son pinturas de las virtudes o vicios morales que aparecen expresadas en las distintas obras de Dios y de la naturaleza 
y que, contempladas rectamente, las acomodamos a nuestras prácticas con gran placer, pero de un modo que es el nuestro, no el de Dios o el de la naturaleza... Pero se dirá que imitamos a la naturaleza y a Dios precisamente cuando hayamos ajustado nuestras costumbres a los modelos de virtudes que Dios y la naturaleza nos han puesto ante los ojos. Pues la naturaleza es la guía de una vida buena y feliz.]

Queda, pues, claro que su fuente es la naturaleza, que, aunque no sea inteligente, todo lo hace por una finalidad, pues tras ella se encuentra Dios, que siempre obra con razón. Además, la naturaleza nos ofrece cosas reales. Y Taurello quiere pintar en sus emblemas realidades naturales de las que se nutra nuestra moral. Rechaza, entonces, como fuente emblemática las fábulas de los poetas y no encontramos en su obra, por ejemplo, emblemas mitológicos, pues tratan cosas irreales; y tampoco admite las antiguas hazañas de los héroes, que pertenecen, dice, más a los ejemplos que a las parábolas de donde derivan los emblemas (b2v-3v).

Hay, además, una utilidad añadida en las cosas naturales, corpóreas y reales: que muchas veces se presentan a nuestros sentidos para mostrarnos lo incorpóreo que escapa a nuestros sentidos. De hecho, otro argumento que le sirve a Taurello para reforzar su propósito de tomar como modelo a la naturaleza para sus emblemas morales (b5v-6r) es que también Dios simboliza con elementos de la naturaleza cosas divinas: el espíritu santo se manifestó como paloma; los animales que Pedro vio en éxtasis designaban a los pueblos que iban a recibir la gracia de Dios (Act. 10.10-15); la semilla enviada a la tierra es el reino o la palabra de Dios; la vid es Cristo y sus fieles (Joh. 15); el maná es el alimento celeste (Ex. 11).

No obstante, hay cosas naturales a las que determinados magos, curanderos y médicos impostores atribuyen propiedades admirables y milagrosas, utilizando además el nombre de Dios y las Escrituras para engañar a los ignorantes y justificar sus acciones. Taurello, en este caso, rechaza cualquier poder milagroso que puedan tener los amuletos y talismanes y condena las cosas que, aun siendo naturales, puedan producir efectos, no naturales, sino directamente emanados del demonio, como es, por ejemplo, el caso de los ungüentos, especialmente el unguentum chirurgorum y el unguentum constellatum, o también los encantamientos (b6v-7r). Se trata, claramente, de un rechazo de la magia. Por ello, el emblematista debe huir de todas estas prácticas sobrenaturales que nos alejan del camino de la virtud y seguir simplemente a la naturaleza como modelo a imitar, pero no de una forma irracional, sino con recta ratio (término estoico), con una doble precaución: no imitar cualquier cosa natural, pues eso es un error; y no enseñar con la emblemática lo que va en contra de las buenas costumbres, pues tal cosa es una maldad: 
Dum autem naturam sectamur, recta ratione nobis est progrediendum, ne tamquam caeci a via virtutis aberremus. Qua in re duplex est cautio: tum ne quidvis imitemur; tum etiam ne quod contra bonos mores est emblematice doceamus. In illo error est; in hoc etiam est malicia (b7v-8r).

[Y mientras vamos en pos de la naturaleza, hemos de avanzar con recta razón, para que no nos apartemos, como los ciegos, del camino de la virtud. En esto hay una doble precaución: no imitar cualquier cosa y no enseñar con la emblemática lo que va en contra de las buenas costumbres. En lo primero, es error; en lo segundo, también malicia.]

En efecto, la ira en un perro o la voracidad y ferocidad en un lobo son naturales y conformes a la naturaleza animal, pero no son deseables en la naturaleza humana, pues el hombre con su recta ratio sabe abstenerse y contenerse y a eso es lo que hay que incitar al hombre. Animarle con emblemas a la ira o la ferocidad sería un error. Y, si uno se ha visto ofendido por algún leve motivo, tampoco debemos pintar unos duros escollos en el mar que rechacen y destrocen a las naves que la tempestad lanza contra ellos, pues eso sería animarle a una venganza extrema, iría contra la moral cristiana y, en suma, sería una maldad por parte del emblematista. Lo que hay, pues, que imitar son las cosas naturales que no se oponen a nuestra naturaleza humana y que pueden adaptarse a nuestra moral para encauzar al lector por el camino de la moral.

Y es que el emblematista, nos advierte Taurello, no debe ejercer de moralista. Más bien es el filósofo moral el que, como especialista, debe fijar los preceptos morales y éticos, mientras que la labor del poeta emblemático ha de ser exclusivamente la de ilustrar dichos preceptos con emblemas, porque con la pintura y los versos tales preceptos se comprenden y asimilan mejor (b8v-c1r):

Res namque naturales emblematica insertione et applicatione ad mores nostros ethicae fiunt et formam quandam moralem concipunt, quae certis virtutum praeceptis continetur et describitur (c1r-v).

[Pues las cosas naturales, con la inserción de emblemas y su aplicación a nuestras costumbres, se convierten en éticas y reciben una especie de forma moral que está contenida y descrita por los preceptos ciertos de las virtudes.]

En este sentido, los temas naturales que Taurello elige para ilustrarnos los preceptos morales son de diferente índole. Toma ejemplos del mundo animal y así aparecen en sus emblemas el cangrejo, el cocodrilo, el perro, el erizo, el jabalí, el lobo, el pájaro con su canto, el escorpión, el oso, etc. También el mundo vegetal está presente, con la ortiga, las espigas de trigo, la manzana, diferentes árboles y sus frutos, la hierba, variadas plantas con sus raíces y espinas, la palmera, etc. Asimismo, encontramos el agua, el hielo, 
el humo y el fuego, el curso de los ríos, las olas y los barcos navegando, el sol (Febo). Y también hallamos como fuente de emblemas cosas que el hombre ha fabricado con algún arte o técnica (ars), siguiendo también en ello a la naturaleza: la noria que impulsa el agua, la balanza, la fragua (con el fuego y las brasas), los cristales, la pelota, etc. En todo ello Taurello busca siempre su conexión con la naturaleza universal y, más concretamente, con la naturaleza específica del hombre, vinculando su mensaje al camino de la virtud. Así, por ejemplo, anima a la juventud, a quien dedica su obra, a actuar con la prudencia del cangrejo. Efectivamente, la obra comienza con un emblema titulado Ante retrorsum («Antes hacia atrás») dedicado a la juventud que se dedica al estudio de la prudencia (Ad iuventutem prudentiae studiosam):

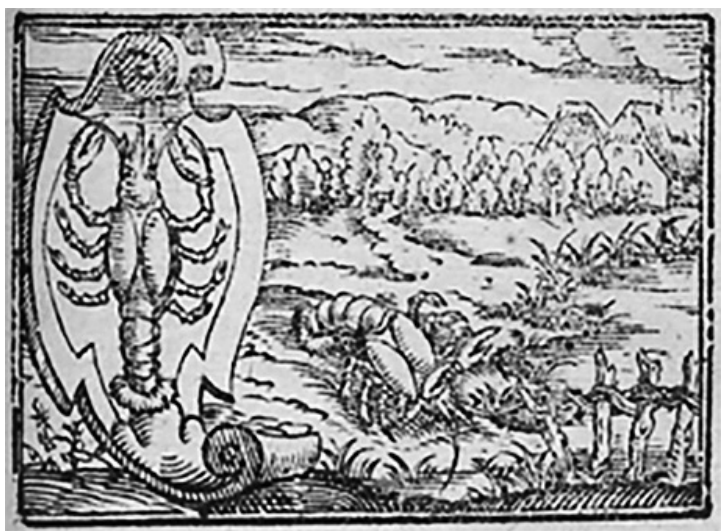

Cum licet ancipitis sectabere commoda cancri,

Et quovis disces vivere posse solo:

Qui fraudatus aquis: sicco tamen aere vivit:

Et lento properans itque, natatque gradu.

Hostem quando fugit, qui prospicit ante: retroque

Paulatim carpit quas iuvat ire vias.

Si nocet ire, gradum revocabis; at ante quid obstet

Spectabis rebus prospiciesque tuis (A1r).

[Cuando te sea lícito, perseguirás las ventajas del anfibio cangrejo Y aprenderás a poder vivir en cualquier suelo.

Cuando se ha visto engañado por las aguas, vive, sin embargo, en seca atmósfera,

Y, apresurándose con lento paso, camina y nada.

Cuando huye del enemigo él, que lo ve por delante y por detrás,

Selecciona poco a poco los caminos que le son útiles recorrer.

Si te perjudica avanzar, darás marcha atrás; pero observarás antes

Qué te supone un obstáculo y mirarás por tus propios intereses.] 
Aconseja moralmente a los jóvenes que se dedican al estudio de la prudencia que se guíen en la vida al modo del cangrejo, que puede vivir en agua y en tierra; que camina y nada lentamente, pero sin pausa; que ve venir siempre al enemigo, tanto por detrás como por delante, sabiendo escoger siempre la vía por donde esquivarlo; y que si, no puede avanzar o vencer, sabe retroceder, atento siempre a los obstáculos que pueda encontrar y fijando su punto de mira en sus propios intereses. Quizás tuvo por modelo La Morosophie de Guillaume de la Perrière (Lyon, 1553), quien en su emblema LXI ofrece la pintura de un cangrejo observado por varios hombres, con el siguiente poema:

Vt quoquoversum graditur cogente timore

Ambulat et cancer dexteritate pari,

Vtile sic etiam nostros invertere mores

(Postulat hoc si res aut patiatur) erit.

[Igual que en todas direcciones anda, si el temor le obliga,

$\mathrm{Y}$ anda el cangrejo con igual destreza,

Así también nos será útil cambiar nuestras costumbres,

Si la circunstancia lo exige o lo consiente.]

Y, como buena parte de sus emblemas va dirigida a jóvenes, no faltan pinturas y epigramas donde quede reflejado cuál es el amor moralmente verdadero, como el emblema 39: Roseo rosa vivit odore («la rosa vive mientras huele a rosas») dirigido a Juan Neuburger de Alkmaar (Holanda), escrito en endecasílabos falecios y dísticos elegíacos:

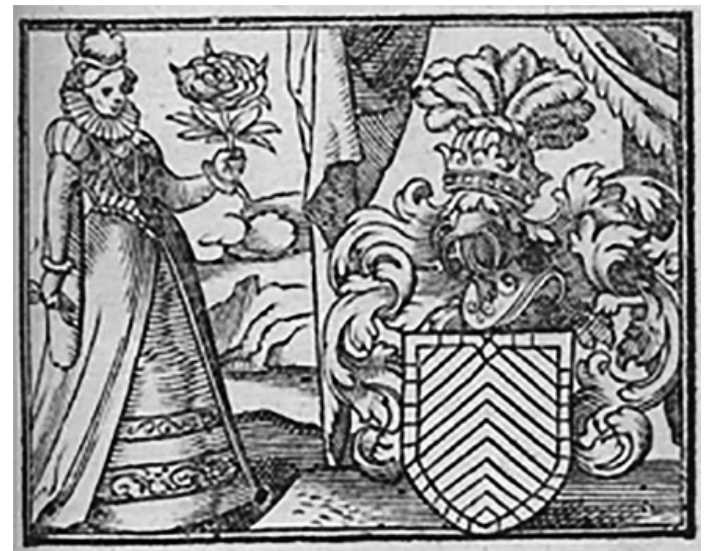

Fragrantes roseo rosas odore

Pergratus decorat color, sed idem

Multis rebus inest color, rosarum

Vnus cum sit odor comes perennis. 
Conservant humana duae consortia dotes:

Hic amor et certa est hic in amore fides.

At si desit odor non est rosa vera colore,

Talis et inconstans est amor absque fide (E7r).

[A las rosas que exhalan olor a rosas

Las realza su agradable color, pero este mismo

Color se halla en muchas cosas, pues sólo

El olor es compañero eterno de las rosas.

Dos prendas conservan los consorcios humanos:

El amor y la fidelidad verdadera en el amor.

Si falta el olor no es la rosa verdadera en su color,

Tal cual es también inconstante el amor sin fidelidad.]

Vemos, pues, la destreza poética de Taurello, capaz de escribir no sólo dísticos elegíacos, sino también endecasílabos falecios e incluso estrofas sáficas y alcaicas. La variatio de temas, todos relativos a la naturaleza, pero de índole diversa, queda también reflejada en la variatio formal del metro. Un rasgo de originalidad.

Y, en fin, aunque sean palpables influencias de otros autores anteriores, los Emblemas de Taurello son originales. No obstante, nos queda la duda a propósito del emblema 2, titulado Leviter si tangis, adurit ( $« \mathrm{Si}$ lo tocas suavemente, escuece») y dedicado al jurista Markus Christoph Gugel de Nuremberg (1576-1626):

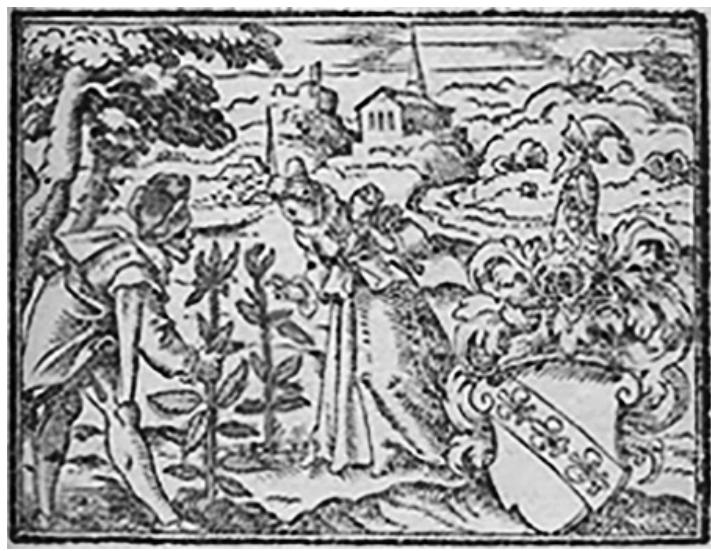

Vrticam si quis contingat molliter, uret:

Et timidas laedet tacta borago manus.

Haec tamen intrepido franguntur spicula pressu:

Hacque omnis subito pellitur arte dolor.

Res age: non magnis nec neglige viribus hostem,

Sed leve quo poteris robore tolle malum (A2r). 
[Si uno toca suavemente la ortiga, escuece;

Y la borraja, si la tocas con manos tímidas, hiere.

Pero estas espinas se rompen si las presionas sin miedo

Y de esta manera se evita todo dolor.

Ponte manos a la obra: no desprecies al enemigo con pequeñas fuerzas,

Pero el mal leve expúlsalo con toda la contundencia que puedas].

Este emblema, con el mismo lema, lo encontramos ya en 1590 en Camerario con el número lXviII de su Primera Centuria de Símbolos y Emblemas tomados del mundo de las hierbas (fols. S1v-S2r). Camerario explica en su comentario en prosa que la ortiga, por los finos y agudos espinos de sus hojas, si se toca ligeramente, causa un gran picor; en cambio, si se aprieta fuerte con la mano, el daño es menor. El mensaje moral, según Camerario, es que los peligros pequeños, si se desprecian y no se les planta cara al instante, al final acaban agrandándose y causan no pocas molestias a los hombres. Luego Camerario aduce un refrán alemán: «el enemigo pequeño y la herida exigua nunca deben descuidarse» y otras fuentes poéticas, incluidos Focílides y Persio. Y acaba su comentario indicando que alguien (quidam) compuso un docto poema sobre este Symbolus, transcribiendo ese anónimo epigrama en dísticos elegíacos. Pues bien, salvo alguna pequeña variante textual, el poema que Camerario transcribe en 1590 como de alguien desconocido es precisamente el que cinco años después Taurello incluye en su libro de emblemas como suyo.

¿Se apropió descaradamente Taurello de un poema que no era suyo? ¿O el poema era de Taurello y, al no tenerlo publicado, lo introdujo en su libro Camerario diciendo simplemente que su autor era el indefinido quidam?

\section{Conclusiones}

Hemos realizado un estudio de los Emblemata physico-ethica, de Nicolás Taurello, un libro que, aun habiendo sido tratado y citado en obras sobre emblemática ${ }^{4}$, carecía de una investigación más o menos amplia que tocara las cuestiones editoriales de la obra, sus circunstancias de composición, las intenciones del autor al componer este tipo de literatura emblemática y, en fin, sus temas principales.

En este sentido, hemos visto que las dos ediciones en vida del autor son las que realmente importan para el estudio de su obra, siendo la segunda la más amplia y completa. Hemos observado también las dificultades que tuvo Taurello para costear la impresión de su obra y cómo hubo de acudir al patrocinio económico de personajes relevantes de la época. Asimismo, hemos

\footnotetext{
4 Por ejemplo, por Lüthy (2012: 122-129), Visser (2005: 119) o Hakansson (2001: 154-156).
} 
concluido que a Taurello le mueve una intención pedagógica, especialmente dirigida a la juventud, para formarla moralmente en los preceptos éticos cristianos extraídos de la realidad natural que nos rodea, que en última instancia es obra de Dios. Y, para que la doctrina tenga una mejor aceptación y asimilación por parte de los jóvenes, la envuelve en el ropaje placentero de las pinturas (emblemas) y de la poesía, intentando conjugar, como preceptuaba Horacio, lo utile con lo dulce y el prodesse con el delectare (Hor., Ars 333 ss.). Y, aunque Taurello puede haber tenido como fuente a algunos autores anteriores, como, por ejemplo, Reusner, la iniciativa de confeccionar unos emblemas cuyos preceptos morales estén tomados de la «física», esto es, de la Natura, no deja de tener cierta originalidad.

\section{Bibliografía}

\section{Fuentes}

Camerario, I. (1590): Symbolorum et emblematum ex re herbaria desumtorum Centuria una. Norimbergae, impensis J. Hoffmanni \& H. Camoxii.

Leibniz, G.G. (1768): Opera omnia, vi. Genevae, De Tournes.

Taurello, N. (1595): Emblemata physico-ethica. Noribergae, excudebat P. Kaufmann.

- (1602): Emblemata physico-ethica. Noribergae, typis C. Lochneri.

- (1617): Emblemata physico-ethica. Noribergae, in bibliopolio S. Halbmayeri.

\section{Estudios}

Bernat Vistarini, A. y Cull, J.T. (1999): Enciclopedia Akal de Emblemas españoles ilustrados. Madrid, Akal.

Cacheda Barreiro, R.M. (2006): La portada del libro en la España de los Austrias menores. Un estudio iconográfico. Tesis Doctoral. Universidad de Santiago de Compostela.

Davies, N. (2005): God's Playground. A History of Poland. Volume I. The Origins to 1795. Oxford, oup.

Folaron, S. (2002): Philosophie der Menschenwürde nach Nikolaus Taurellus. Czestochowa.

Groos, K. (1894): «Taurellus Nicolaus». Allgemeine Deutsche Biographie, xxxviI, Leipzig, págs. 467-471.

Håkansson, H. (2001): Seeing the word. Jonh Dee and Renaissance Occultism. Lund, Lunds Universitet.

Jaumann, H. (2004): Handbuch Gelehrtenkultur der Frühen Neuzeit. Band 1: Bio-bibliographisches Repertorium. Berlin-New York, Walter de Gruyter, s.v. «Taurellus, Nikolaus», pág. 647.

Lengenfelder, K. (1977): «Die Emblemata der Hohen Schule zu Altdorf». Altnürn berger Landschaft Mitteilungen, 26, págs. 13-20. 
Lüthy, C. (2012): David Gorlaeus (1591-1612). Amsterdam, Amsterdam University Press.

Martin, C. (2014): Subverting Aristotle: Religion, History and Philosophy in Early Modern Science. Baltimore, J. Hopkins University Press.

Visser, A.S.Q. (2005): Joannes Sambucus and the learned image. Leiden-Boston, Brill. 